\title{
Functional Thalamocortical Synapse Reorganization from Subplate to Layer IV during Postnatal Development in the Reeler-Like Mutant Rat (Shaking Rat Kawasaki)
}

\author{
Shuji Higashi, ${ }^{1}$ Kyoji Hioki, ${ }^{2}$ Tohru Kurotani, ${ }^{3}$ Nicholas Kasim, ${ }^{4}$ and Zoltán Molnár ${ }^{1,4}$ \\ ${ }^{1}$ Division of Neurophysiology, Graduate School, Kyoto Prefectural University of Medicine, Kawaramachi-Hirokoji, Kyoto 602-8566, Japan, ${ }^{2}$ Central Institute \\ for Experimental Animals, Kawasaki, Kanagawa 213, Japan, ${ }^{3}$ Department of Visual Neuroscience, Research Institute of Environmental Medicine, Nagoya \\ University, Furo-cho, Chikusa-ku, Nagoya 464-8601, Japan, and ${ }^{4}$ Department of Human Anatomy and Genetics, University of Oxford, Oxford OX1 3QX, \\ United Kingdom
}

Transient synapse formation between thalamic axons and subplate neurons is thought to be important in thalamocortical targeting. Shaking rat Kawasaki (SRK), having reversed cortical layering similarly observed in reeler mouse, provides an interesting model system to test this idea. The spatial and temporal pattern of excitation was investigated using optical recording with voltage-sensitive dyes in thalamocortical slice preparations from SRK. At postnatal day 0 (P0), a strong optical response was elicited within the superplate of the SRK in the cell layer corresponding to subplate in wild-type (WT) rats. By P3, this response rapidly descended into deep cortical layers comprised of layer IV cells, as identified with 5-bromo-2'-deoxyuridine birthdating at embryonic day 17 . During the first 3 postnatal days, both the subplate and cortical plate responses were present, but by P7, the subplate response was abolished. Tracing individual axons in SRK revealed that at P0 - P3, a large number of thalamocortical axons reach the superplate, and by P7-P10, the ascending axons develop side branches into the lower or middle cortical layers. Synaptic currents were also demonstrated in WT subplate cells and in SRK superficial cortical cells using whole-cell recording. These currents were elicited monosynaptically, because partial AMPA current blockade did not modify the latencies. These results suggest that the general developmental pattern of synapse formation between thalamic axons and subplate (superplate) neurons in WT and SRK is very similar, and individual thalamic arbors in cortex are considerably remodeled during early postnatal development to find layer IV equivalent neurons.

Key words: reeler; superplate; SRK; thalamocortical slice; subplate; voltage-sensitive dye; optical recording

\section{Introduction}

Projections from specific thalamic nuclei transmit sensory information with different modalities to the cerebral cortex (Jones, 1985). During embryonic development, thalamocortical axons accumulate in the subplate (Luskin and Shatz, 1985; Kostovic and Rakic, 1990) before they innervate the overlying cortex to establish their ultimate synaptic contacts, mostly with layer IV neurons (Catalano et al., 1991, 1996). Previous studies suggest that thalamic axons establish synapses with subplate neurons during prenatal periods (Kageyama and Robertson, 1993; Allendoerfer and Shatz, 1994; Herrmann et al., 1994), and white matter stimulation elicits synaptic responses on individual subplate neurons

\footnotetext{
Received June 18, 2004; revised Dec. 18, 2004; accepted Dec. 23, 2004.

This work was supported by grants from the Japanese Ministry of Education, Science, and Culture (Grant-in-Aid for Encouragement of Young Scientists 08780790 to S.H.) and from the Medical Research Council UK (GO 300200; Grant ID 65860 to Z.M.).

We are grateful to Prof. Nobuhiko Yamamoto, Dr. Erin Jacobs, Dr. Rosalind Carney, and Anna Hoerder for their critical reading of a previous version of this manuscript and to Prof. Minoru Kimura for continuous encouragement and support. We thank to Alex Thompson for helping with some of the tracing experiments. We are grateful to Prof. Nobuhiko Yamamoto for his kind gift of CS-56 antibody.

Correspondence should be addressed to Dr. Shuji Higashi, Division of Neurophysiology, Graduate School, Kyoto Prefectural University of Medicine, Kawaramachi-Hirokoji, Kyoto 602-8566, Japan. E-mail: higashi@koto.kpu-m.ac.jp.

D0I:10.1523/JNEUROSCI.4023-04.2005

Copyright $\odot 2005$ Society for Neuroscience $\quad$ 0270-6474/05/251395-12\$15.00/0
}

(Friauf and Shatz, 1991; Hanganu et al., 2002). Some of the subplate neurons are known to develop axonal projections into the cortical plate, and it was suggested that they might start relaying activity patterns into the cortical plate and marginal zone before thalamic input gets fully established (Friauf and Shatz, 1991). Early ablation of subplate neurons in primary visual cortex prevents the invasion of thalamic axons; later ablation precludes the formation of ocular dominance and orientation columns in cats and ferrets (McConnell et al., 1989; Ghosh and Shatz, 1992; Kanold et al., 2003). These anatomical and physiological observations suggest that subplate neurons orchestrate the ultimate thalamocortical synapse formation during development by integrating into the forming cortical circuitry (Arber, 2004). However, currently, there is very little data on the functional properties of these transient circuits. It is not known how the transient circuitry will get transferred to the permanent one. The reeler mutation, with its reversed relative position of the subplate and cortical plate, provides a good system to further examine the sequence and pattern of this process. Morphological studies showed that in reeler mutant mice and shaking rat Kawasaki (SRK), the thalamocortical axons extend toward the superplate before the projections descend to the cortical plate (Caviness, 1976; Aikawa et al., 1988; Yuasa et al., 1994; Molnár et al., 1998). 
However, the functional responses elicited through these presumed synapses and their relationship with cortical activation patterns have never been documented. The optical recording technique with voltage-sensitive dyes, combined with axon tracing and other anatomical techniques (Crair et al., 1993; Higashi et al., 1996, 1999, 2002), is ideally suited to test these ideas on the migration of the functional responses from the early generated neurons to layer IV.

In this study, we present evidence that the first functional thalamocortical synaptic responses are formed on the equivalent early generated neurons of the subplate in wild-type (WT) and superplate neurons in SRK. The subsequent rearrangement of the activation pattern from the temporary to ultimate target (layer IV cells) follows a similar time frame, but in the opposite direction in SRK and WT. These results suggest that functional synapse formation with early generated neurons might have an important role in the establishment of ultimate synapses with layer IV cells.

\section{Materials and Methods}

\section{Animals}

All animal experimental procedures were conducted with the approval of the Committee for Animal Research, Kyoto Prefectural University of Medicine (Kyoto, Japan). To obtain a first generation of heterozygote SRK offspring, we introduced a male heterozygote SRK from the Central Institute for Experimental Animals into a facility of Kyoto Prefectural University of Medicine and mated it with WT female Wistar rats from Shimizu Jikkenzairyo (Kyoto, Japan). Heterozygote males were crossed with heterozygote females, and the strain was established by backcrossing in our facility for experimental animals. Anatomical and behavioral characteristics of SRK were well conserved in every generation and very closely resembled previous reports (Aikawa et al., 1988). The day of sperm detection was defined as embryonic day 0 (E0), and the day of birth was defined as postnatal day 0 (P0).

\section{Birthdating with 5-bromo-2'-deoxyuridine}

5-Bromo-2'-deoxyuridine (BrdU) injection and immunohistochemical staining procedures were similar to those described by Yamamoto et al. (1992). Briefly, BrdU (100 mg/kg; Wako, Osaka, Japan) was injected intraperitoneally into the pregnant mother at E13 or E14 for labeling subplate neurons and at E17 for labeling layer IV cells. For histological analysis, P0 thalamocortical slices were fixed with $4 \%$ paraformaldehyde in $0.1 \mathrm{M}$ phosphate buffer for $30 \mathrm{~min}$ to $1 \mathrm{~h}$, which was replaced with $70 \%$ ethanol solution and kept at $4^{\circ} \mathrm{C}$. In some cases, $\mathrm{P} 10$ rats were transcardially perfused with $4 \%$ paraformaldehyde solution, and the brains were postfixed and subsequently treated as described for the slice preparations. After cryoprotection with $30 \%$ sucrose, the slices were serially sectioned at $80 \mu \mathrm{m}$, incubated with $2 \mathrm{~N} \mathrm{HCl}$ for $90 \mathrm{~min}$, and rinsed with $0.15 \mathrm{M} \mathrm{Na}_{2} \mathrm{~B}_{4} \mathrm{O}_{7}$ and PBS. Sections were incubated with anti-BrdU (1:5; Becton Dickinson, Mountain View, CA) as the primary antibody overnight, followed by fluorescein isothiocyanate (FITC)-labeled anti-mouse IgG (1:100; Cappel, Durham, NC) for $2 \mathrm{~h}$ at $4^{\circ} \mathrm{C}$. The sections were observed with an epifluorescent microscope, and fluorescent images were obtained with a confocal microscope (MRC-500; Bio-Rad, Hemel Hempstead, UK).

\section{Immunohistochemistry}

E19 and P0 wild-type and SRK brains were immersed into 4\% paraformaldehyde solution for 1 or $2 \mathrm{~d}$. Thalamocortical sections were cut at 50 $\mu \mathrm{m}$ thickness, incubated with 1:1000 rabbit anti-calretinin (Chemicon, Temecula, CA) or 1:200 monoclonal anti-chondroitin sulfate proteoglycan (CS-56; Seikagaku, Tokyo, Japan) at $4^{\circ} \mathrm{C}$ overnight, and then followed by Alexa 488-labeled anti-rabbit IgG or cyanine 3-labeled antimouse IgM for $2 \mathrm{~h}$ at room temperature. Fluorescent images of the sections were taken by a DP-70 camera (Olympus, Tokyo, Japan). Cerebellum blocks were fixed with $4 \%$ paraformaldehyde and cryoprotected with $30 \%$ sucrose in PBS at $4^{\circ} \mathrm{C}$. Cerebellum block was sagittally cut at $100 \mu \mathrm{m}$ thickness, and then these sections were stained with cresyl violet for determining phenotype. All antibodies were diluted in $50 \mathrm{~mm}$ PBS containing $0.1 \%$ Tween 20 for BrdU staining or containing $0.1 \%$ Triton $\mathrm{X}-100$ for calretinin staining. In the case of chondroitin sulfate proteoglycan staining, no detergent was used.

\section{Thalamocortical axon tracing and cytochrome oxidase staining} Iontophoretic dextran biotin (BDA; 5\%; Molecular Probes, Eugene, OR) injections were performed as reported previously (Higashi et al., 1999, 2002). Briefly, a glass micropipette containing BDA was inserted into the thalamus of the slice preparation, and $0.5 \mathrm{~Hz} 5 \mu \mathrm{A}$ positive current was applied through the pipette for $15 \mathrm{~min}$. The injections were performed at two to four loci in the thalamus. Ten to $14 \mathrm{~h}$ after BDA injection into the thalamus of $\mathrm{P} 0, \mathrm{P} 10$, or $\mathrm{P} 22-\mathrm{P} 24$ slices, they were fixed with $4 \%$ paraformaldehyde and cryoprotected with $30 \%$ sucrose, and serial sections were cut at $100 \mu \mathrm{m}$ and stained with FITC-labeled avidin (1:100; Vector Laboratories, Burlingame, CA) for 2-4 h. Fluorescent images were acquired using confocal microscopy, and montage images were assembled using NIH Image (version 1.62) and Adobe Photoshop (version 5.02; Adobe Systems, San Jose, CA) computer software. For tracing single thalamocortical axons, 1, $1^{\prime}$-dioctadecyl-3,3,3',3' tetramethylindocarbocyanine (DiI) crystals were inserted into the thalamus of whole brains (P3 WT, $n=5$; P8 WT, $n=5$; P3 SRK, $n=5$; P8 SRK, $n=5$ ) fixed with $4 \%$ paraformaldehyde overnight, which were stored for 2-4 weeks at room temperature in $0.1 \mathrm{M}$ PBS (with $0.05 \% \mathrm{NaN}_{3}$ ). Two hundredmicrometer-thick coronal sections were cut using a Vibroslicer (Leica, Nussloch, Germany). DiI-labeled axons were traced with using a camera lucida attached onto a Leica (DMR) microscope (P3 WT, $n=11$; P8 WT, $n=10$; P3 SRK, $n=16$; P8 SRK, $n=23$ ).

P10 WT and SRK rats ( $n=3$ for each) were transcardially perfused with $2.5 \%$ glutaraldehyde and $2 \%$ paraformaldehyde solution in $0.1 \mathrm{~mm}$ phosphate buffer, and then brains were removed into PBS containing $30 \%$ sucrose for cryoprotection. Tangential cortical hemisphere sections were cut at $100 \mu \mathrm{m}$ thickness with a freezing microtome, and then cytochrome oxidase $(\mathrm{CO})$ staining was performed by standard procedure (Wong-Riley, 1979).

\section{Optical recording, data analysis, and whole-cell recording}

We prepared thalamocortical slices at three postnatal ages: (1) at P0 within the first $15 \mathrm{~h}$ after birth (most cases within $3 \mathrm{~h}$ ), (2) at P3, and (3) at P7-P10. The preparation of the thalamocortical slices, staining with voltage-sensitive dyes, the optical recording procedure, and the data acquisition sequence have been described previously (Agmon and Connors, 1991; Higashi et al., 1999, 2002). Briefly, 500- $\mu$ m-thick slices were cut at $45^{\circ}(\mathrm{P} 0)$ to $50^{\circ}(\mathrm{P} 10)$ oblique angles from the coronal plane. No tilt was used in the longitudinal axis at P0. The slices were stained with voltage-sensitive dye $(0.05 \mathrm{mg} / \mathrm{ml} \mathrm{RH482;} \mathrm{Nippon} \mathrm{Kankoh-Shikiso,}$ Okayama, Japan) for $10 \mathrm{~min}$, and a bipolar stimulation electrode was inserted into the thalamus directly under microscopic observation. Stimulation current intensity varied from 0.3 to $1.5 \mathrm{~mA}$ among the slices, but usually $1 \mathrm{~mA}$ of stimulation current, which was close to the maximum intensity, was used. A total of 512 frames of optical response image $(128 \times 128$ pixels $)$ were collected at $0.6 \mathrm{~ms}$ intervals and stored in a computer. For data analysis, the raw data value at every pixel of each frame was divided by the corresponding pixel value of the reference image, and then every pixel value of each frame was spatially filtered by Gaussian matrix $(3 \times 3)$ for noise reduction on a UNIX workstation. Average images were obtained from six (P0) or four (P3 and P10) frames. To collect mostly monosynaptic responses and to increase spatial signalto-noise ratio, the frames were selected from the period during 19.2 and $22.8 \mathrm{~ms}$ (SRK) or during 18 and $21.6 \mathrm{~ms}$ (WT) after stimulation at P0, during 13.65 and $16.05 \mathrm{~ms}$ (average) at P3, and during 7.4 and $10 \mathrm{~ms}$ (average) at P10. These frames contained the first peak response frame (P3 and P10) and/or corresponded to the time of presynaptic fiber volley disappearance ( $\mathrm{P} 0)$. In these average frames, signal intensities of pixel values were collected five times along five different cortical columnar lines, and these intensities along these five cortical columnar lines were averaged and columnar cortical depth from the surface was normalized by a cortical gray matter thickness. The cortical gray matter thickness was determined by the average of three different columnar lines in each reference image. These three columnar lines included areas in which optical 
response appeared in the cortex. Microsoft (Redmond, WA) Excel 98 was used for statistical analysis.

Slices were mounted in a submersion recording chamber set on an upright microscope (BX50WI; Olympus), and stimulation electrodes were inserted as described above. Internal solution contained (in $\mathrm{mM}$ ): $117 \mathrm{~K}$-gluconate, $13 \mathrm{KCl}, 10 \mathrm{NaCl}, 1 \mathrm{CaCl}_{2}, 5 \mathrm{MgSO}_{4}, 5 \mathrm{EGTA}, 10$ HEPES, $1 \mathrm{Na}$-ATP, $0.3 \mathrm{Na}$-GTP, $5 \mathrm{Na}$-phosphocreatine, Lucifer yellow (0.3\%; Molecular Probes), and biocytin (0.1\%; Sigma, St. Louis, MO), $\mathrm{pH}$ 7.3. Subplate cells in WT and superplate cells in SRK were identified with a $60 \times$ water immersion lens using infrared differential interference contrast optics (Olympus). The stimulation electrode was placed in the thalamus as in the case of optical recording using less than one-half of maximum intensity. Whole-cell current at $-70 \mathrm{mV}$ was recorded with an EPC-7 amplifier (HEKA, Lambrecht, Germany) at room temperature and stored in a computer through DigiData1200 series interface and pClamp software (Axon Instruments, Foster City, CA). After seal rupture, series resistance was not compensated but was continuously monitored.

\section{Results}

\section{Morphological characteristics of cortex in SRK}

It has been demonstrated that a short deletion in the reelin gene causes the reeler-like phenotype of SRK (Ikeda and Terashima, 1997; Kikkawa et al., 2003). In a typical litter generated from a SRK heterozygote female and male (usually 10-12 pups), one to three pups $(\sim 25 \%)$ show motor deficit and characteristic reeling behavior 2 weeks after birth. Rats with this phenotype die $\sim 2$ months after birth. At any postnatal age examined, the brains of these pups exhibited similar cerebellar and cerebral morphological abnormalities as described in the reeler mutant mouse. They could be clearly distinguished from WT brains. The SRK brains appeared smaller, and the cerebellar cortex had abnormal foliation in the mutants. We could identify the SRK (homozygote) mutants through the characteristic abnormal external cerebellar morphology, as reported previously (Aikawa et al., 1988; Ikeda and Terashima, 1997).

Figure 1 demonstrates typical morphological differences between SRK and WT rat cerebral cortex and the position of cells born at E13 and E17, determined by birthdating. This morphology is very similar to reports on the reeler mouse (Caviness et al., 1988). Nissl staining revealed a different cytoarchitecture in SRK from the WT (Fig. 1). SRK cortex did not show clear layering at any age. In contrast, in WT rats, some of the cortical layers could be easily identified at $\mathrm{P} 0$, and all layers were unambiguous by $\mathrm{P} 10$. In SRK cortex, the subplate, marginal zone, or dense cortical plate could not be identified. Although the average cortical gray matter thickness (measured just above the dorsal edge of the striatum on Nissl-stained sections) appeared slightly smaller in SRK than in WT rats, our measurements did not show significance. At P0, P3, and P7-P10, the average cortical thickness in SRK was $743 \pm 18$ $\mu \mathrm{m}(n=8), 900 \pm 61 \mu \mathrm{m}(n=5)$, and $1635 \pm 167 \mu \mathrm{m}(n=5)$, and in WT, the average cortical thickness was $800 \pm 82 \mu \mathrm{m}(n=$ $10), 942 \pm 79 \mu \mathrm{m}(n=5)$, and $1630 \pm 112(n=5)$, respectively.

To confirm whether cortical layering in SRK is indeed a similar inversion of normal inside-out neurogenic gradient as described in the reeler mouse (Caviness et al., 1988), we compared the distribution of birthdated cells in the cortex of SRK with that in the cortex of WT rats. BrdU was injected into pregnant mothers at E13 or E17 of the gestational period. To predominantly label the subplate and superplate neurons in the cortex, BrdU injections were performed at E13 $(n=5)$. To label layer IV cells, the injections were made at E17 $(n=4)$. Immunohistochemical staining for BrdU revealed that some cells became postmitotic shortly after the BrdU injection and contained heavily labeled nuclei (Fig. $1 M, N)$. In WT, the E13 BrdU-labeled cells corre-
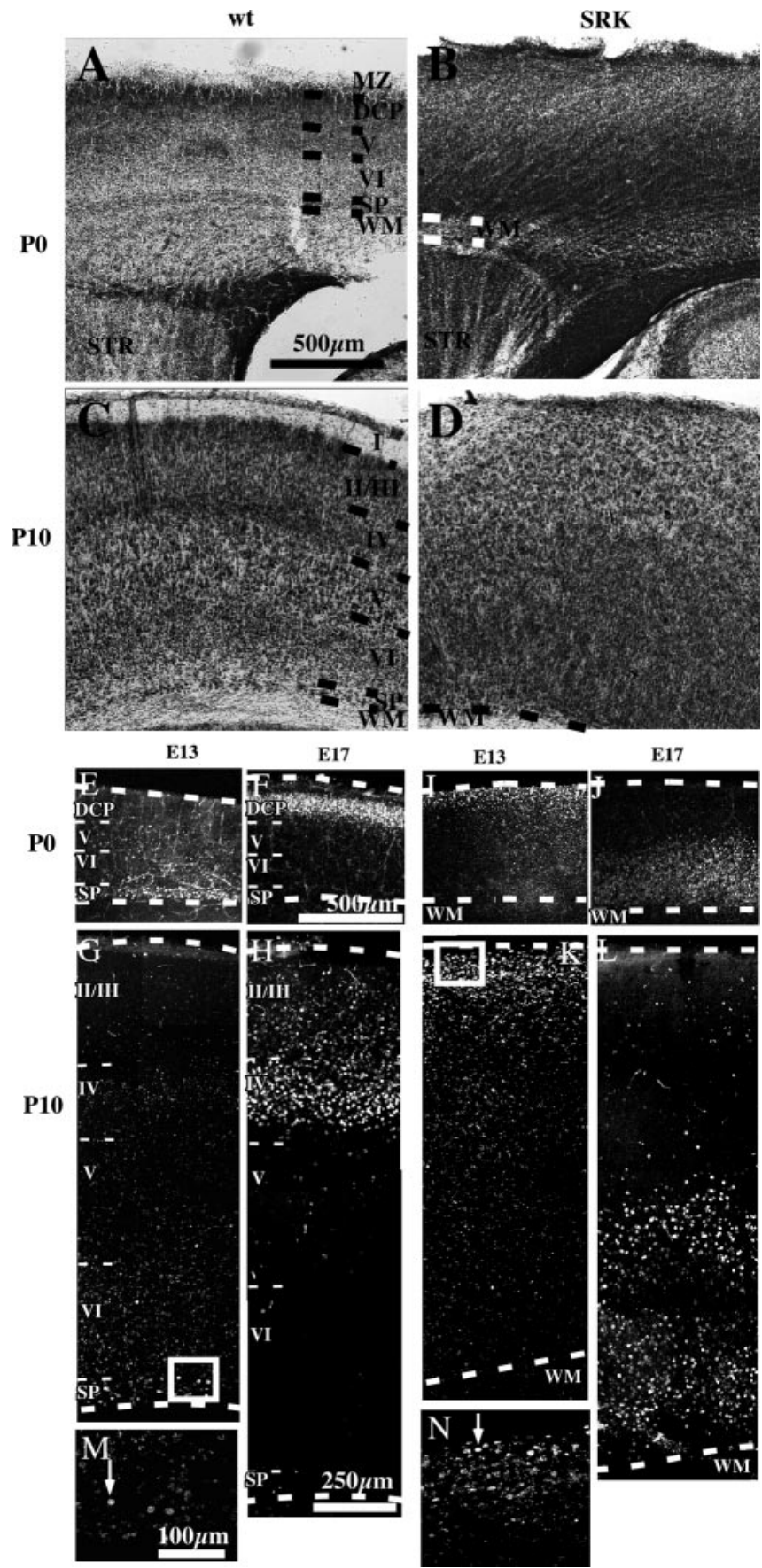

Figure 1. Nissl staining revealed altered organization of the cerebral cortex in SRK. Photomicrographs were taken from coronal sections at $\mathrm{P} 0(A, B)$ and at $\mathrm{P} 10(C, D)$. $A$ and $C$ were obtained from WT rats, and $B$ and $D$ were obtained from SRK. Birthdating revealed the reversed, outside first-inside last development of the cortical layers in SRK. Confocal microscopic images demonstrate the distribution of BrdU-immunoreactive cells, which were labeled at $E 13(E, G, I, K, M$, $N)$ and at $E 17(F, H, J, L)$ in WT $(E-H, M)$ and SRK $(I-L, N)$ rats. $E, F, I$, and $J$ were obtained at PO, and $G, H$, and $K-N$ were obtained at P10. E13 labeled cells were distributed in deep cortical layers of WT $(E, G)$, whereas they were in a superficial part of the cortex in SRK $(I, K)$. In contrast, E17 labeled cells were distributed in upper layers of WT $(F, H)$ but were found in a deeper part of the SRK cortex $(J, L)$. $M$ and $N$ provide examples of brightly labeled cells (arrows) at subplate in WT (from the region indicated at $G$ ) and at superplate in SRK (from the region indicated with a box at $K$ ), respectively. Dashed lines depict the pial surface of the cortex and the borders of the different cortical layer $(E-H)$. MZ, Marginal zone; DCP, dense cortical plate; II/III, layers II and III; IV, layer IV; V, layer V; VI, layer VI; SP, subplate; WM, white matter; STR, striatum. Scale bars: (in $A, F) A-F, I, J, 500 \mu \mathrm{m}$; (in $H$ ) G, H, K, L, $250 \mu \mathrm{m}$; (in M) M, N, $100 \mu \mathrm{m}$. 
sponding to subplate neurons were located in deep cortical layers (Fig. $1 E, G$ ), whereas the E17 labeled cells, corresponding to layer IV cells, were located in superficial layers of the cortex at P0 (Fig. $1 F, H)$. In contrast to these, in SRK mutants the E13 birthdated neurons were found at the cortical surface at P0 and P10 (Fig. $1 I, K)$, similar to the reeler mouse. At $\mathrm{P} 0$, the average location depth of heavily BrdU-immunoreactive cells birthdated at E13 (Fig. $1 N$ ) was $\sim 70 \mu \mathrm{m}$ below the pial surface (calculated from three SRK slices; $n=30$ cells; $68.7 \pm 10.3 \mu \mathrm{m}$ ). From the E17 BrdU injection, the heavily labeled cells were found in deep cortical layers between 250 and $600 \mu \mathrm{m}$ (calculated from four SRK slices; $n=40$ cells; $450 \pm 89.5 \mu \mathrm{m}$ ) at P0 and not close to the pial surface at any of the ages studied in SRK (Fig. $1 J, L$ ). These results suggest that in the SRK, the preplate does not split into marginal zone and subplate, just as it was described for the reeler mouse (Caviness et al., 1988). The superplate corresponding to the subplate and marginal zone of the WT is formed immediately below the pial surface in SRK. The rest of the cortical layering appears reversed in SRK compared with that observed in WT. Furthermore, these BrdU labeling experiments suggest that some of the early generated neurons (subplate and superplate neurons) survive to least $\mathrm{P} 10$.

Calretinin (CR) and chondroitin sulfate (CS-56) immunoreactivity reveals the position of the subplate cells in normal rats (Bicknese et al., 1994; Fukumitsu et al., 1998). We examined the distribution of these markers at E19 and P0 SRK to confirm that the superficial cortex of SRK corresponds to superplate. At E19, subplate was stained with both antibodies (supplemental material, available at www.jneurosci.org), but the staining was not specifically and exclusively localized to it. In SRK at E19, CR immunoreactivity was found at the superficial cortex, and CS-56 also stained superficial strongly. At P0, the immunoreactivity for CR and CS-56 was even more spread to the cortical plate; nevertheless, both antibodies confirmed the inverted position of the labeled layers in SRK. These results suggest that superficial cortex of SRK corresponds to subplate.

\section{Thalamocortical tracing experiments in SRK}

To investigate the thalamocortical axon targeting in SRK cortex, we traced these projections in thalamocortical slices. These slices were prepared similarly as those for optical recording experiments, and thalamic axons were anterogradely labeled from BDA iontophoretical injections in the ventrobasal complex at P0, P10, and P22-P24 (Fig. 2) or with carbocyanine dye crystal placements (Fig. $2 K$, DiI). The present study revealed no significant structural changes in SRK thalamus using Nissl staining confirming the previous findings (Welt and Steindler, 1977; O'Brien et al., 1987). Consistent with abnormal cortical layering, which mirrors that observed in reeler mutant mice, the thalamocortical axonal projection pattern in SRK was similar to the one observed in reeler mutant mouse. At P0, in both SRK and WT rats, BDAlabeled thalamocortical axons extended through the striatum and internal capsule in similar fascicles. The trajectory of the axon fascicles in this region did not seem to differ between SRK and WT rats (compare Fig. 2, $A$ and $E$ ). In WT rats, however, the majority of thalamic axons accumulated under the cortical gray matter, and only some of them extended into the cortical plate (Fig. 2A,B), whereas in the SRK, the labeled thalamic axons extended to the cortical surface along oblique trajectories in similar fascicles as were observed in the striatum (Fig. 2E). At P8-P10, the DiI- or BDA-labeled axon terminals formed patches in layer IV, and they did not reach the cortical surface in WT (Fig. $2 C, D, K)$, whereas in SRK, some labeled axons still extended to the cortical surface, although they started to develop arbors in the lower layers (Fig. $2 \mathrm{H}, \mathrm{K}$ ). Some of the axons reaching the cortical surface in SRK seemed to turn around and descend toward deep cortical layers. These axonal patterns were still observed at P24 and P22 (Fig. 2, I and J, respectively). Some axons formed complex branches in the middle of the cortical layers (Fig. 2I), although there were axons extending their process to the cortical surface without branching (Fig. 2J). In these BDA-labeled P24 thalamocortical slices, we followed 15 axons. Ten axons reached the cortical surface directly, and five formed branches in deep layers without a loop to the surface of the cortex.

In addition to BDA experiments in slices, we traced single thalamic axon arbors with DiI in whole brains from the ventrobasal complex and reconstructed some selected individual axons in 200- $\mu \mathrm{m}$-thick coronal sections using camera lucida at P3 and P8. Figure $2 K$ shows examples of reconstructed single thalamic arbors in WT and SRK. In WT, we occasionally observed thalamic axons extending into the marginal zone at P0 (2 of 10) and P3 (0 of 10) (Fig. $2 K$, third panel in top row). Interestingly, in the SRK at P3 and P8, we observed axons that did not ascend to the pial surface yet still formed arbors in the middle of the cortical plate ( 1 of 16 terminals at $\mathrm{P} 3$ and 5 of 23 arbors at P8; see example in third panel in bottom row of Fig. 2). These reconstructions were performed on $200 \mu \mathrm{m}$ slices and thus cannot be considered complete. Nevertheless, these results suggest that the majority of thalamocortical axons initially extend toward early generated cells of superplate neurons regardless of their differing relative location to other cortical layers in SRK, but this initial loop might not be maintained at later stages in some of the thalamocortical arbors.

\section{Optical response in SRK and wild-type rat during postnatal periods}

Previous anatomical studies by others and our own optical recording studies suggest that in WT rat and mouse, thalamocortical axons not only extend toward subplate but also form functional synapses (Friauf and Shatz, 1991; Herrmann et al., 1994; Higashi et al., 2002). Subsequently, during the first few postnatal days, thalamic axons establish synapses with layer IV cells (Agmon et al., 1993; Crair et al., 1993; Kageyama and Robertson, 1993; Molnár 1998; Higashi et al., 1999, 2002). If this developmental sequence is conserved in SRK, the spatial pattern of optical response in the cortex and its postnatal development should be reversed in the mutant rat compared with WT, according to the inverted cortical layering of SRK. We stimulated the thalamus of slice preparations stained with a voltage-sensitive dye (RH482) and recorded the optical responses at P0, P3, and P7-P10. We compared the spatio-temporal patterns of neural excitation propagation in the cortex of SRK with those of WT at these ages (Figs. 3-5).

At P0 (Fig. 3), neural excitation propagated through the internal capsule and reached the cortex in both WT $(n=13)$ and SRK $(n=13)$ rats. In WT rats, the fast DNQX- and APV-resistant neural excitation reached just above the white matter to the subplate and layer VI cells. This fast response was followed by a more sustained, longer response in subplate and layer VI. Apart from the first spiky response, the rest were induced by glutamate receptor activation, because the application of glutamate antagonists (40 $\mu \mathrm{M}$ DNQX; Tocris Cookson, Ballwin, MO and $50 \mu \mathrm{M}$ APV; Sigma) diminished them (Fig. 3B1,B2,E). The spatial propagation pattern of neural excitation within the cortex was different in SRK from that of WT rat. In SRK, spike-like excitation activity directly reached the cortical surface subsequently fol- 

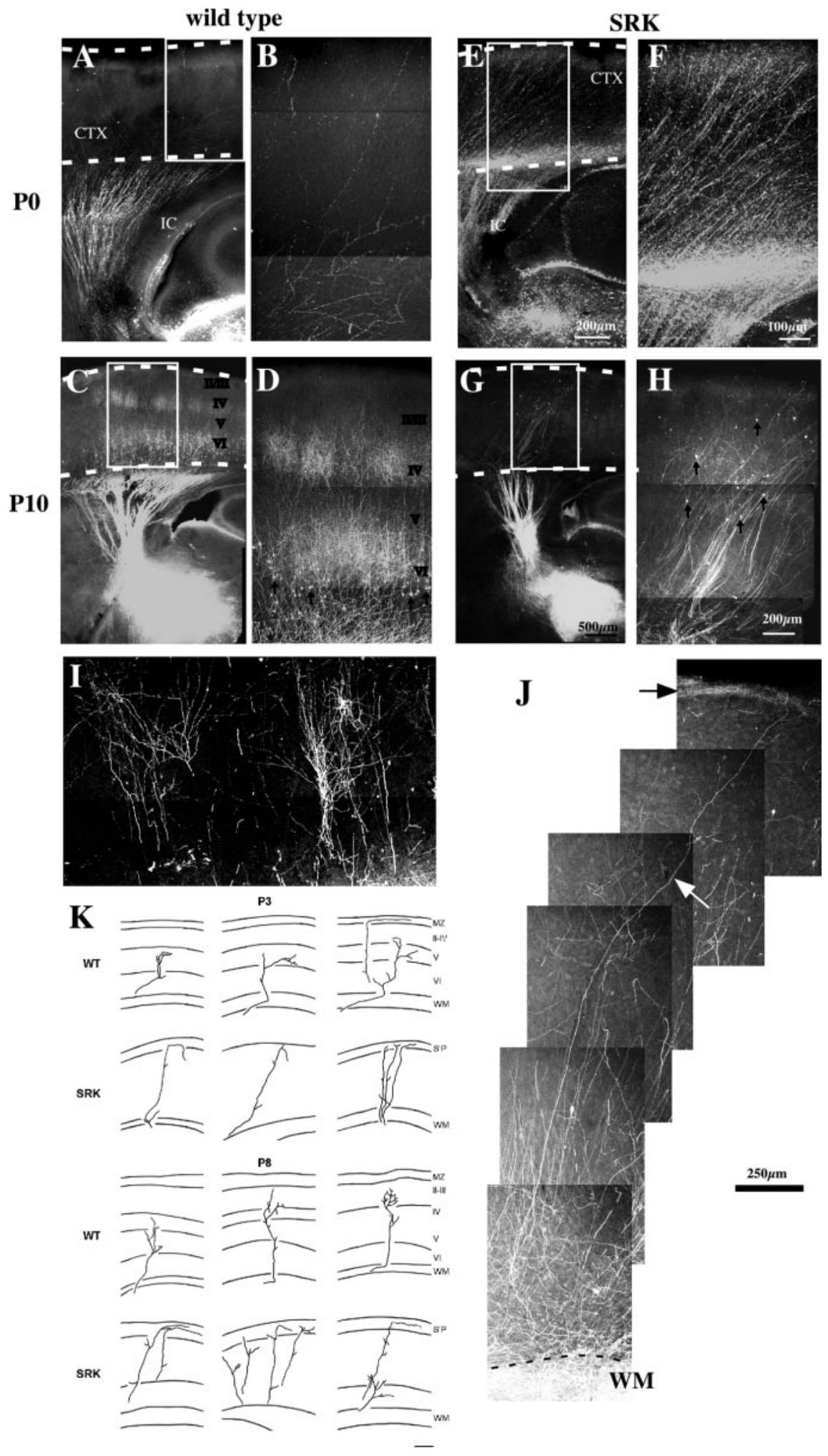

Figure 2. Thalamocortical projections revealed from BDA injections into the ventrobasal complex of the dorsal thalamus in thalamocortical slice preparations of WT ( $A-D)$ and $S R K(E-H)$ rats at birth $(P O ; A, B, E, F)$ and at $P 10(C, D, G, H) . B, D, F$, and $H$ are high-power images from the areas indicated with boxes in panels $A, C, E$, and $G$, respectively. In WT rats at $P O(A, B)$, thalamocortical axons entered the cortex and started to branch within the cortical plate, and only few axons could be followed to the pial surface ( $B)$. In SRK at P0, thalamocortical axons crossed the cortex in oblique fascicles, and the majority reached the pial surface. There were no or very few backlabeled cortical cells observed at this age. In WT, by P10, thalamocortical projections formed terminals in layers VI and IV. Their distribution followed the periphery-related patterns in layer IV. There were numerous backlabeled cells in layer VI (arrows in D). In the SRK at P10, oblique fascicles were still present, but the thalamic projections descended from the pial surface or they formed branches as they traversed the middle cortical layers. More numerous backlabeled cells were scattered across the upper two-thirds of the cortex (arrows at $H$ ) compared with PO. Dashed lines mark the cortical surface and the border of white and gray matters. I illustrates the complex arbors formed in the middle of the cortex in SRK at P24. At P22, some thalamic axons (white arrow in J) still extended toward the cortical surface (black arrow in $J$ ) without prominent collaterals in SRK. K shows examples of single thalamocortical axons reconstructed with camera lucida from the primary somatosensory cortex at P3 and P8. CTX, Cortex; IC, internal capsule. Scale bars: (in $E, G) A, C, E, G, 500 \mu \mathrm{m}$; (in J) I, J, 250 $\mu \mathrm{m}$; (in $H) D, H, 200 \mu \mathrm{m} ; K, 200 \mu \mathrm{m} ;$ (in F) B, $F, 100 \mu \mathrm{m}$. 
lowed by a long-lasting and stronger response at the cortical surface (Fig. 3D1). This site correlates to the location of the superplate and early generated cortical plate neurons. In SRK, the long-lasting cortical responses were also induced through glutamate receptor activation as in WT, because the perfusion of a glutamate antagonist mixture greatly reduced them, and only the fast spike-like response, corresponding to thalamic fiber volley, remained (Fig. $3 D 2, F)$. The synaptic response seen just after fiber volley arrival was mainly located at deep cortical layers in WT rats but at the cortical surface in SRK (see Fig. 6).

In our previous studies, we demonstrated that in WT rats, the optical response extended into the upper cortical layers during the first postnatal days (Crair et al., 1993; Higashi et al., 1999). At P3, the responses at the superficial cortical layers in the SRK $(n=5)$ and deep cortical layers in the WT $(n=7)$ rats were observed similarly as seen at P0, but in addition to these areas, the response extended into the entire depth of the cortex in both SRK and WT rats (Fig. 4 B1,D1). The directions of these spatial expansions were in opposite directions in SRK and WT rats. In WT rats by P3 (Fig. $4 B$ ), the response ascended into more superficial cortical layers than observed at P0, whereas in SRK (Fig. 4D), the optical response descended into deeper cortical layers than those seen at P0. Although superficially, the spatial pattern of the optical response seemed to be similar between SRK and WT rats at P3, the location of the peak optical response along cortical column was significantly deeper in SRK from that of the WT rats (see Fig. 6).

By P7 to P10 in WT rats $(n=11)$ (Fig. $5 B 1$ ), the initial optical responses were localized in layers IV and VI, and the longerlasting sustained neural excitation spread to the other cortical layers (Crair et al., 1993; Higashi et al., 1999). The responses in layer IV showed a sharp time course and a clear periphery-related clustering (corresponding to barrels) (Fig. 5B1,F). The responses seen in layer II/III showed a slower time course than the responses in layers IV and VI. This reflects the monosynaptic and polysynaptic origin of the two types of signals (Higashi et al., 1999), because the response in layer IV followed repetitive stimuli, and part of the response still remained after high divalent cation solution perfusion, whereas the response in layer II/III did not show these properties. In SRK, the responses were first seen in the middle and lower cortical layers before spreading into more superficial layers $(n=10)$ (Fig. $5 D 1)$. The time course of the response at the deep cortical part (Fig. 5F) showed a sharper rising phase than that seen in upper cortical layers. Spatial pattern broadly extended in deep cortical layers of SRK (Fig. 5D1). On the

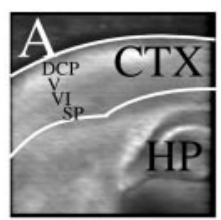

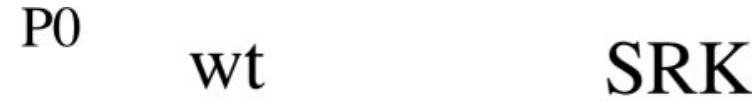

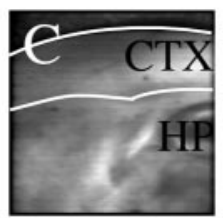

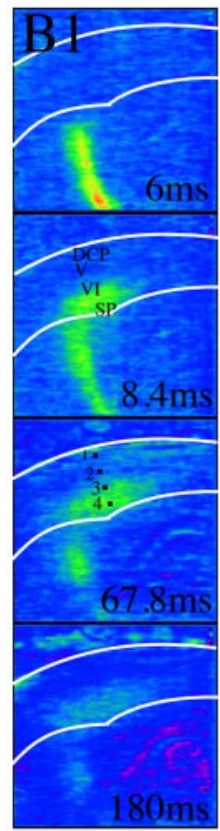

normal $\mathrm{E}$

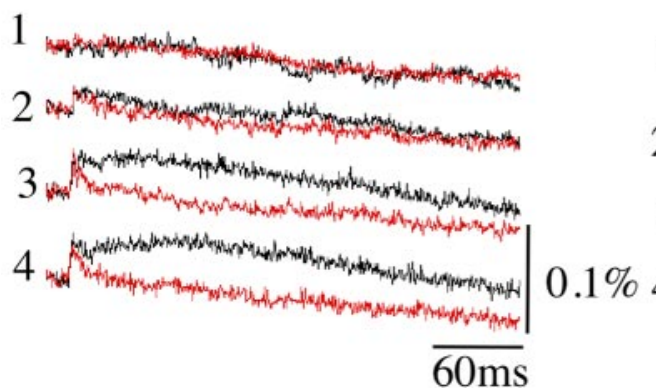

Figure 3. Optical responses were recorded from WT $(A, B, E)$ and $\operatorname{SRK}(C, D, F)$ at $P 0$. $A$ and $C$ are reference images indicating the outline of the cortex (CTX) and hippocampus (HP). B1 and D1 show four images selected at four different times from a representative optical response consisting of 512 images under control conditions and also four images selected at the same time points as $B 1$ and $D 1$ after the perfusion of the glutamate antagonist (DNQX and APV) $(B 2, D 2)$. The time after stimulation is indicated in the bottom right corner of the each optical image of B1 and D1. In WT, the strong sustained response (left, after 67.8 and $180 \mathrm{ms)}$ appeared in deep cortical layers and was abolished by the glutamate receptor antagonist perfusion (right), whereas in SRK the synaptic responses (left) mainly appeared close to the cortical surface. These were also abolished after the bath application of DNQX and APV (right). Time courses of four selected cortical loci (see location at B1,67.8 ms panel for WT and D1,7.8 ms panel for SRK) before (black) and after (red) the antagonist application $(E, F)$. DCP, Dense cortical plate; SP, subplate. other hand, synaptic responses seen in subplate and superplate at $\mathrm{P} 0$ and $\mathrm{P} 3$ were no longer seen in either the WT rats or in SRK.

Next, we quantitatively analyzed the developmental changes in the spatial pattern of the optical responses. An average response image was obtained for each age from each experiment around the spike response. That period corresponds to the end of the presynaptic fiber volley at $\mathrm{P} 0$ and/or the period of the peak response at $\mathrm{P} 3$ and $\mathrm{P} 10$. At $\mathrm{P} 10$, the presynaptic fiber volley could 


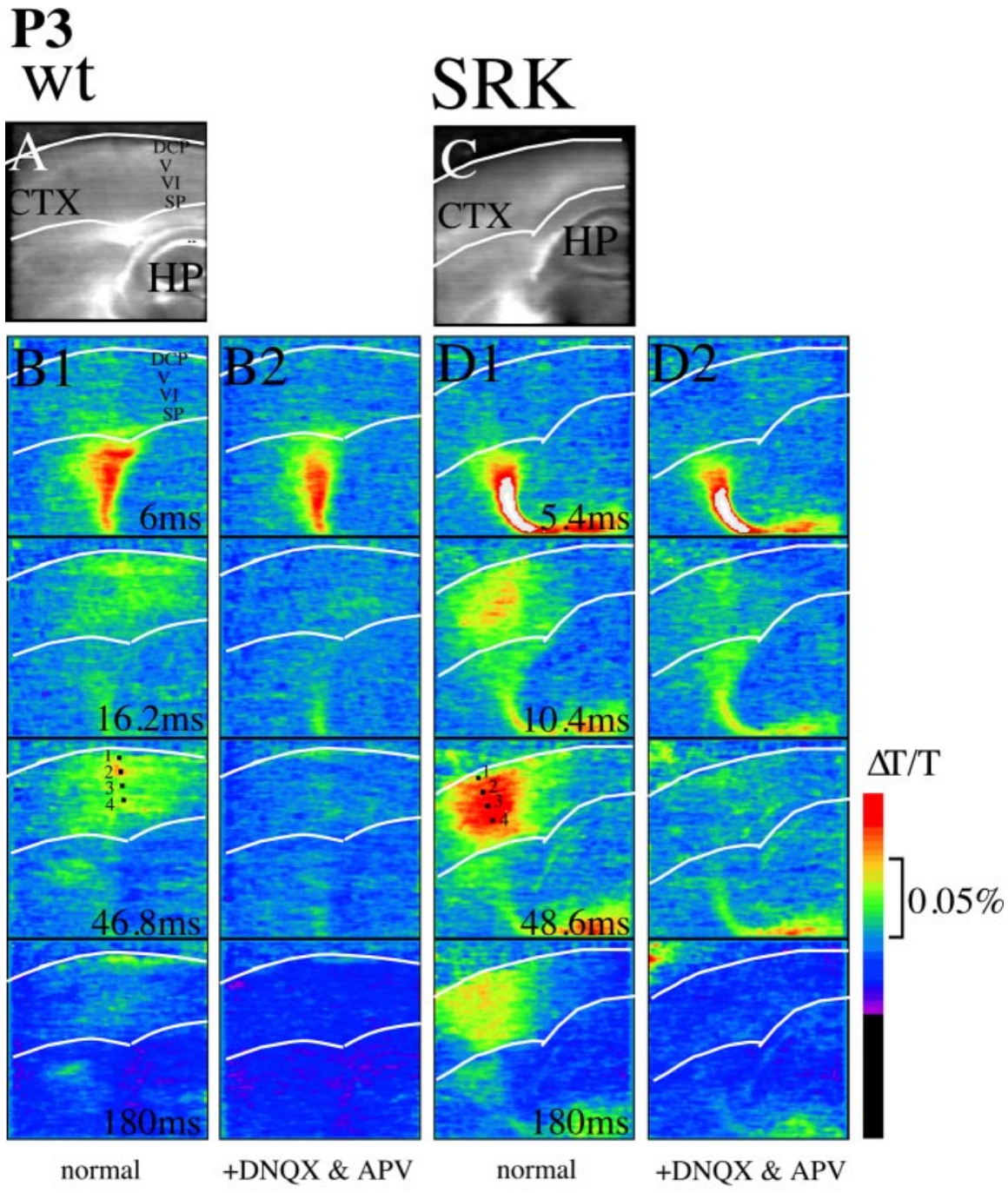

$\mathrm{E}$

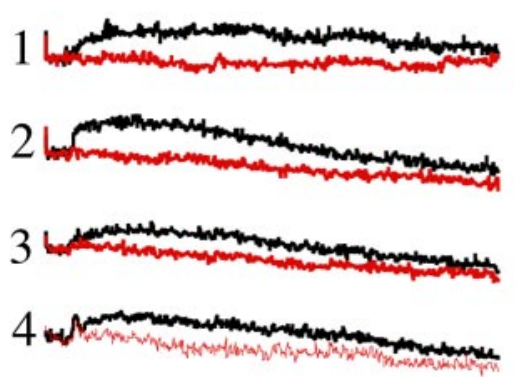

$\mathrm{F}$
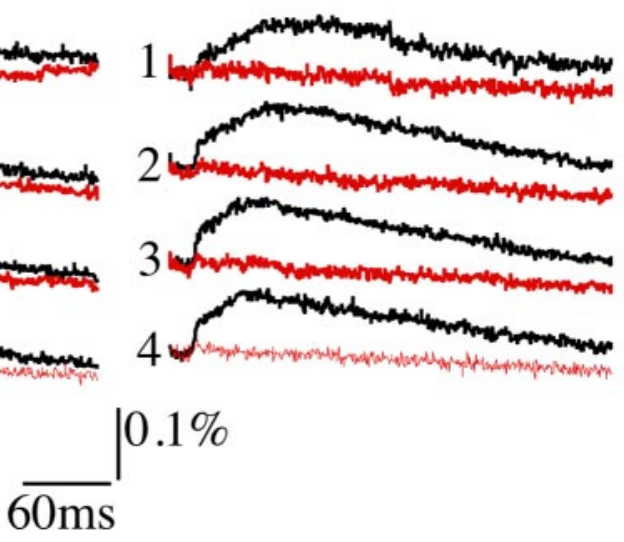

Figure 4. Optical responses were recorded from $W T(A, B, E)$ and $S R K(C, D, F)$ at $P 3$. Figure 4 is structured similarly to for Figure 3. By P3, the sustained (glutamate receptor antagonist-sensitive) cortical depolarization reached the upper layers in WT (B1 and $B 2$ at 16.2 and $46.8 \mathrm{~ms}$ ), and a more widespread response, spanning almost all cortical layers, was observed in the SRK (D1 and D2 at 10.4, 48.6, and $180 \mathrm{~ms})$. CTX, Cortex; HP, hippocampus; DCP, dense cortical plate; SP, subplate. image, and the columnar length was normalized by cortical thickness. Figure 6 shows typical average images at each age in WT and SRK and the average spatial profiles obtained from each image and normalized by cortical gray matter thickness. In WT, the peak was located in deep cortical layers $(0.6 \pm 0.09)$ at P0 and moved toward upper cortical layer IV during postnatal days $(0.19 \pm 0.06$ at $\mathrm{P} 3$ and $0.31 \pm 0.04$ at P7-P10). Meanwhile, the half width of the response was reduced during postnatal days (from $0.52 \pm 0.14$ at $\mathrm{P} 0$, to $0.43 \pm 0.13$ at $\mathrm{P} 3$, and then to $0.14 \pm$ 0.02 at P10). In contrast, in SRK, the peak was located close to the cortical surface at P0 $(0.15 \pm 0.048)$ and then moved toward the deep cortical layers during postnatal days $(0.55 \pm 0.1$ at $\mathrm{P} 3$ and $0.59 \pm 0.1$ at P10). The half width of the response increased during the first 3 postnatal days $(0.32 \pm 0.15$ at $\mathrm{P} 0$ and $0.64 \pm 0.12$ at $\mathrm{P} 3)$ but then substantially decreased by P10, similarly as observed in WT $(0.41 \pm 0.08)$. These results indicate that thalamocortical synapses are initially formed at cortical layers occupied by early generated neurons around birth, and by P10, thalamocortical axons form functional synapses with layer IV cells in both WT and SRK.

\section{Barrel formation in reeler and SRK}

The optical recording results showed that developmental sequence of migration of functional synapse from early generated neurons including subplate or superplate to late-generated target neurons (layer IV cells) occurred similarly in SRK. These results suggest the thalamocortical axons find their target cells in SRK. We investigated whether barrels, which are the functional units of the rodent somatosensory cortex, are formed similarly in SRK as in WT rats. We performed CO staining of tangential cortical sections in P10 SRK and compared them with those from WT rats. Figure 7 shows the typical staining of tangential sections of WT (Fig. $7 A, B$ ) and SRK (Fig. $7 C, D)$. Periphery-related central pattern with normal barrel-like topographic organization of body panel is seen in SRK as well as in WT. The high-power image of CO staining of SRK cortical sections, however, showed that the individual CO-positive patches, corresponding to clustered thalamocortical projections, was not as well defined as that seen in WT, and their size appeared smaller in SRK that in WT. not be followed within the cortex, although propagation of the excitation could be clearly observed between thalamus and cortical white matter. The average spatial response was calculated from five spatial profiles along a cortical column in each average
Excitatory postsynaptic current elicited by thalamic stimulation in SRK and WT rats

The glutamatergic antagonist perfusion results suggest that the optical responses seen in WT rats and SRK reflect synaptic depo- 
larization induced by thalamocortical synapse activation, because the antagonist perfusion abolished the cortical optical responses without the early excitation propagation from thalamus to the cortex. To confirm this at single cell level, we performed whole-cell current recording of P0 SRK and WT thalamocortical slices. Typical current responses are shown in Figure 8. The thalamic stimulation elicited synaptic current with similar latencies in both cases; however, the values appeared slightly longer for SRK (10-15 ms) compared with WT (7-10 ms). These relatively long latencies of synaptic currents revealed with electrophysiology corresponded well to the optical response latencies in WT subplate or SRK superplate. The fast current decay (within 10 to $15 \mathrm{~ms}$ ) also suggests quite mature synaptic contacts. Furthermore, DNQX $(0.25 \mu \mathrm{M})$ greatly reduced the response, but partial responses still remained at the same latency in both cases. These results suggest that the synaptic currents recorded at subplate and superplate are monosynaptically induced by the thalamic stimulation and also support the notion that the early part of the optical responses are mainly attributable to synaptic activity induced by the thalamocortical synapses. This response might then be followed by corticocortical activation.

To statistically analyze the spatial pattern of the early component of the optical responses and thus to study the location of the monosynaptic responses after thalamocortical fiber activation, we averaged six (P0) and four (P3) frames around the end of their presynaptic responses (Fig. 6). These frames reflect the location of the thalamocortical synapses and were consistent with our anatomical results. The location of the responses mirrored the thalamic axon accumulation in the subplate and the subsequent ingrowth toward upper cortical layers in WT rat and mouse (Catalano et al., 1991; Agmon et al., 1993, 1995). At P0, the peak of the responses was located at superficial cortical layers in SRK but at deep cortical layers in WT rats. Subsequently, at P3 and P10, the peak descended into deep cortical layers in SRK but ascended into layer IV in WT rats. The peak locations at P0 were closely correlated with BrdU-labeled cell distribution in both SRK and WT. The location of the peak of the optical responses correlated to the location of the superplate (100- $\mu \mathrm{m}$-thick layer below the pial surface) in SRK, which is similar to the approximate dimensions in reeler mouse (Yuasa et al., 1994). These results suggest that the optical responses are induced on the early generated neurons including subplate neurons of WT rats and superplate neurons of SRK, regardless of their relative position in the cortex.

Optical responses at $\mathrm{P} 0$ were smaller in WT than that in SRK. They also seemed to be slower in WT than that in SRK (Fig. 3B1, $67.8 \mathrm{~ms}, D 1,7.8 \mathrm{~ms}$ ). Latency of the synaptic responses measured

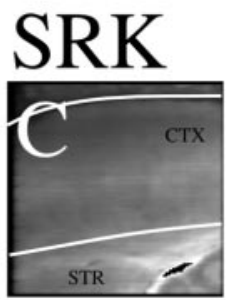

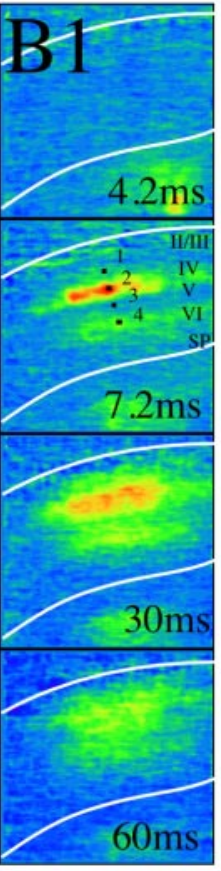

normal

$\mathrm{E}$
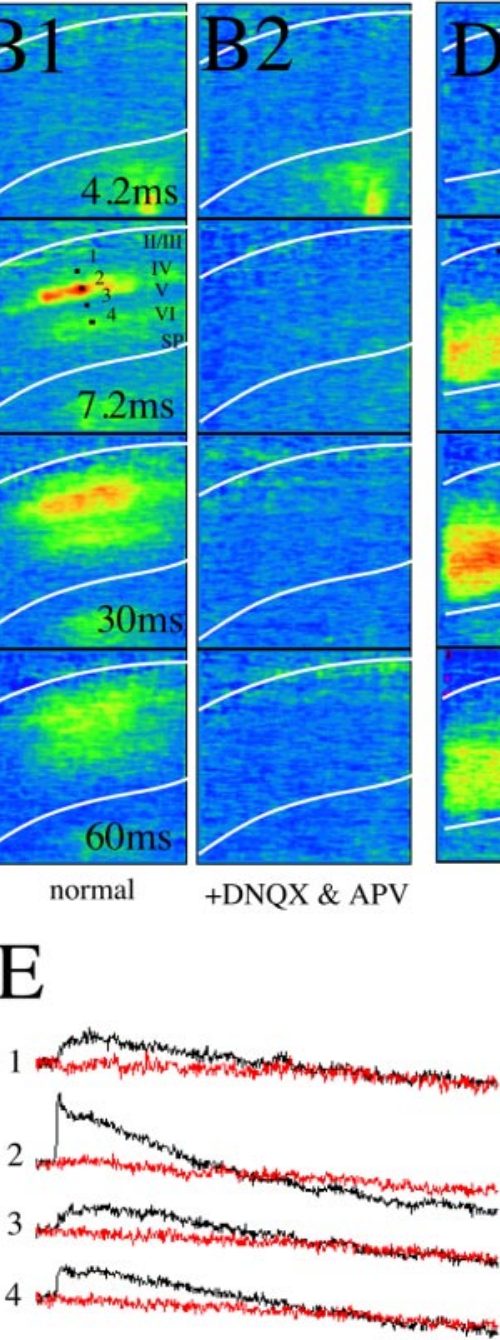

+DNQX \& APV

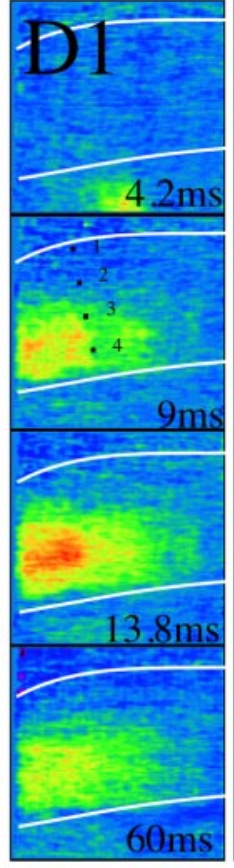

normal

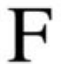

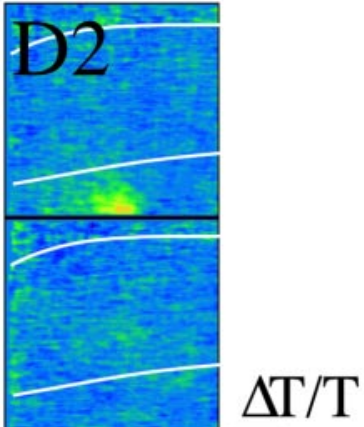

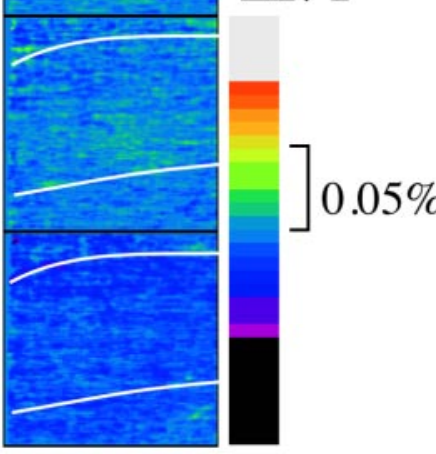

+DNQX \& APV

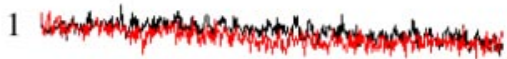

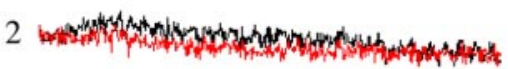

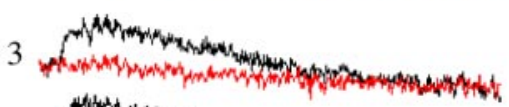

$0.1 \%$

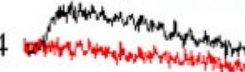

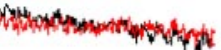

\section{$60 \mathrm{~ms}$}

Figure 5. Optical responses were recorded from WT $(A, B, E)$ and SRK $(C, D, F)$ at P10. At this stage, the DNQX-and APV-sensitive sustained depolarization appeared in layers IV and to a lesser extent in layer VI in the WT, whereas the most intensive depolarization was closer to the lower layers in the SRK. See the legends to Figures 3 and 4 for additional information. SP, Subplate; CTX, cortex.

by whole-cell recording was shorter in WT than those in SRK as shown in Figure 8. The reasons explaining these differences are not clear at present. Nevertheless, both the optical recording and the whole-cell recording revealed similar synaptic responses on subplate cells in WT and on superplate cells in SRK.

\section{Correlation between optical recording, birthdating, and anatomical analysis}

We also have to consider the possibility of whether the optical response at P7-P10 in SRK is generated in layer IV cells. The 


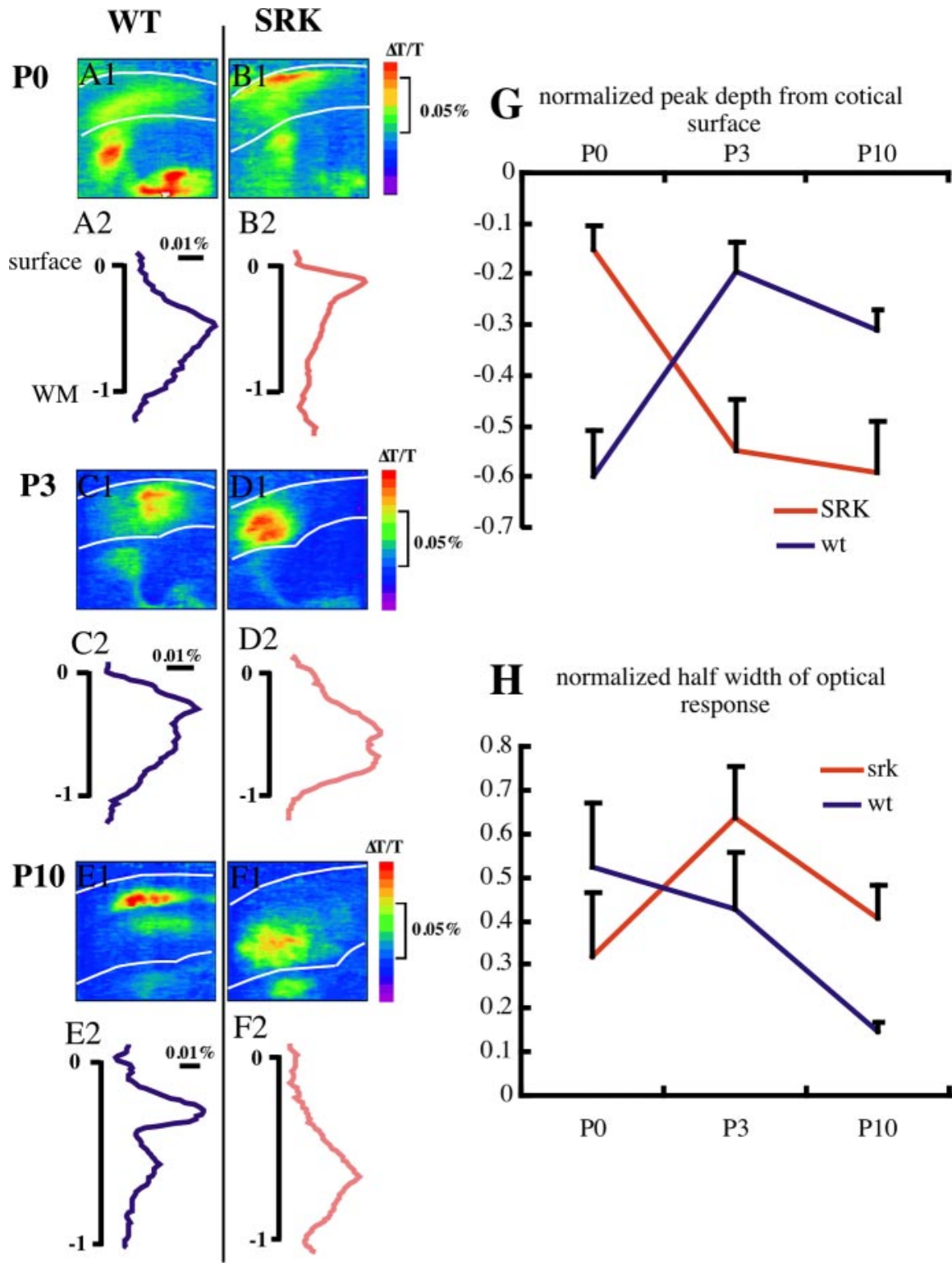

Figure 6. Average optical recording images representative of the period of the beginning of the sustained cortical depolarization at P0 ( $n=13$ in SRK; $n=13$ in WT) or at P3 ( $n=5$ in SRK; $n=7$ in WT) and P10 ( $n=10$ in SRK; $n=11$ in WT). Typical examples of averaged spatial pattern were shown in WT $(A 1, C 1, E 1)$ and SRK $(B 1, D 1, F 1)$ at P0, P3, and P10. The average depth profile for each image shown (A2-F2) was obtained along five columnar lines perpendicular to the cortical layers. Statistical analysis of the peak response position normalized by cortical thickness is shown in $G$. At P0, the peak is located in deep cortical layers in WT but close to the surface in SRK. These peaks have already shifted from deep cortical layer to superficial layer in WT and from surface to deep in SRK at P3. Statistical analysis was performed by Student's t test between SRK and WT at corresponding ages and between $\mathrm{PO}$ and other ages in both SRK and WT rats. $p$ values were $<0.001$. Statistical analysis of half width of the optical response during postnatal periods is shown in $H$. Values of the half width were normalized by average cortical thickness at each age. In WT, during P3 and P10, half widths of the responses were reduced significantly. In SRK, during P0 and P3, half width of the response temporally increased significantly but decreased by $P 10$. There is no significant difference between $P 3$ and $P 10$ at peak position of WT ( $p<0.45$ ), between P0 and P10 at half width of SRK $(p<0.08)$, between SRK and WT in half width at P3 ( $p<$ 0.037), and between P0 and P3 half width in WT ( $p<0.32$ ). Other combinations (among ages in same phenotype or between phenotypes at the same age) were statistically significant ( $p \leq 0.006$ ). Error bars indicated SD. WM, White matter.

spatial peak location of the optical response normalized by cortical gray matter thickness in SRK at P10 was deeper and the half width of the response was wider than that seen in WT rat (Fig. $7 G, H)$. These results are consistent with our BrdU birthdating experiments showing that the E17 labeled cells in SRK are located in deeper cortical layers but spread wider than in WT rats (Fig. $1 H, L)$. Consistent with our present results, previous anatomical studies suggested that barrel formation and thalamocortical axon branching and termination occur in deep cortical layers in reeler mutant mice (Caviness et al., 1976; Bronchti et al., 1999). In addition, optical responses segregated in layer IV of WT rats and a deep cortical layer corresponding layer IV of SRK during P3 and P10. These phenomena are consistent with axonal elongation of thalamocortical projections and terminal formation during postnatal days. Initially, primary axons extend through the cortical plate and then terminal formation starts in layer IV in WT mice (Agmon et al., 1993; Catalano et al. 1996). Therefore, it is feasible that a majority of the initial optical response in deep cortical layer of SRK reflected the synaptic responses between thalamic axons and layer IV cells, which were abnormally located in deep cortical layers in SRK.

\section{Discussion}

Optical responses in the cortex of SRK follow the altered position of subplate cells

We compared the optical responses induced by direct thalamic stimulation in SRK and WT rats and correlated these patterns with the thalamocortical axon arbors and with the position of the cells born at E13 or E17 in subplate or in layer IV, respectively.

The existence of glutamatergic spontaneous and evoked synaptic activity and synaptic immature structures on subplate neurons in normal cortex have been described previously (Friauf et al., 1990; Friauf and Shatz, 1991; Kageyama and Robertson, 1993; Yuasa et al., 1994; Hanganu et al., 2001, 2002; Higashi et al., 2002). Our study is the first to demonstrate this in the superplate of SRK. We also recorded synaptic current by whole-cell recording, and AMPA receptor blockade with DNQX did not modify the latency of the current in superplate cells, indicating monosynaptic contact with thalamocortical axons. Optical responses taken at the time corresponding to the end of the presynaptic fiber volley reliably reflected the distribution of functional thalamic synapses in the cortex (Higashi et al., 2002).

Although the spatial patterns of the optical responses were located in the subplate in WT rats or the superplate in SRK, the responses already extended into upper layers in WT rats and the deep cortical part in SRK at P0. It is possible that these responses contained a monosynaptic thalamocortical component but also a polysynaptic corticocortical component, especially in the phase occurring $>100 \mathrm{~ms}$ after the stimulus. Our previous study using WT rat embryonic thalamocortical slices showed that the optical responses appeared in the subplate in a more localized manner a few days before birth (Higashi et al., 2002). Embryonic recording from SRK could help the further understanding of this 
period. In both WT and SRK, the spatial profiles of the optical responses suggest that the responses are still induced in subplate and in superplate at $\mathrm{P} 0-\mathrm{P} 3$, but they were diminished by $\mathrm{P} 10$.

\section{Roles of early generated transient synapses for development of cortical circuits}

The present study confirms the previous anatomical studies on the reeler mutant mouse (Caviness, 1976; Yuasa et al., 1994; Molnár, 1998) and SRK (Aikawa et al., 1988; Ikeda and Terashima, 1997), demonstrating thalamocortical innervation of superplate, but it also provides the first evidence for functional synapses. Moreover, our optical and electrophysiological recording results suggest that synapse reorganization from subplate neurons to layer IV cells during early developmental stages is a general process for the development of thalamocortical connections in the cortex. Kanold et al. (2003) demonstrated that ablating subplate just after the arrival and just before the ingrowth of thalamic projections did not change the recognition process between thalamic projections and layer IV cells, but it drastically reduced the efficacy of thalamocortical synapses formed. This prevented the formation of ocular dominance and orientation columns. It is, however, still not clear by what mechanisms the transient synapses between thalamic axons and subplate neurons promote the maturation of the ultimate layer IV synapses (Arber, 2004).

In cats, subplate neurons are thought to comprise a transient cell population, because a majority of them disappear during postnatal periods (Luskin and Shatz, 1985; Allendoerfer and Shatz, 1994). In rats, however, a considerable fraction of subplate neurons seem to survive like other cortical plate cells (Robertson et al., 2000). These anatomical results are consistent with BrdU labeling, suggesting the survival of subplate and superplate neurons at P10. By this time, optical responses in subplate in the WT and superplate in SRK have disappeared. Therefore, it is not likely that thalamic axons cannot maintain synapses with subplate neurons because they start to die. Rather, it is more likely that synapses of thalamic axons are actively removed from subplate neurons and simultaneously formed with layer IV cells before their death. One possible function is that subplate neurons transmit neural activity of thalamic axons to the cortical cells and increasing the coherency of neural activity between thalamic axons and other cortical cells to establish efficient thalamocortical synapse on layer IV cells during very early postnatal stages. Hanganu et al. (2002) showed that subplate neurons receive synaptic inputs from other subplate neurons and from cortical plate cells. These results are consistent with our present and previous results showing long-lasting responses induced by thalamic stimulation during embryonic and very early postnatal periods (Higashi et al., 2002). These reflect polysynaptic components and suggest that subplate neurons could integrate into forming cortical circuits.

The optical responses found in the subplate of WT rats and in the superplate of SRK seemed to be diminished during early postnatal development. These findings suggest that synaptic elimination occurs between thalamic axons and subplate (superplate) neurons, while the main axonal process starts to interact with layer IV cells (Fig. 3). Although the process of synaptic elimination is thought to be crucial for refinement of neural circuits and neural plasticity, its molecular mechanisms are still primarily unknown. El-Husseini et al. (2000) reported that the protein postsynaptic density 95 (PSD-95), present at postsynaptic density and binding to other proteins by PSD-95/Discs large/zona occludens-1 motifs, relates to AMPA receptor accumulation on hippocampal excitatory and inhibitory neurons and involved in spine maturation. It has not been elucidated how synaptic responses between thalamic axons and subplate neurons or subplate neurons and layer 4 cells are altered at the single cell level during the perinatal period. One possibility is that after the thalamic input will depolarize layer 4 cells more efficiently, the activation via subplate shall arrive relatively later, and this will trigger the downregulation of PSD-95 expression and so AMPA receptors are not able to cluster at these synaptic sites.

\section{Recognition of layer IV}

Organotypic slice culture studies demonstrated that axonal branching occurred in specific layers, and layer-specific input and output connections were maintained in vitro, suggesting intrinsic mechanisms for cortical layer specificity (Yamamoto et al., 1989, 1992; Bolz et al., 1990; Molnár and Blakemore, 1991, 1999). In SRK, synaptic response progressed from early generated neurons to late-generated neurons similar to WT rats, although cortical layering significantly differed from WT rats. In the case of coculture studies using postnatal cortical explants and embryonic thalamus, thalamic axons still found layer IV without contacting subplate neurons, even if thalamic axons had to extend into the cortex from the cortical surface without traversing through subplate (Molnár and Blakemore, 1991; Yamamoto et al., 1992). These results suggest that some signals from extracellular matrix proteins and/or trophic factors induce axonal stop- 

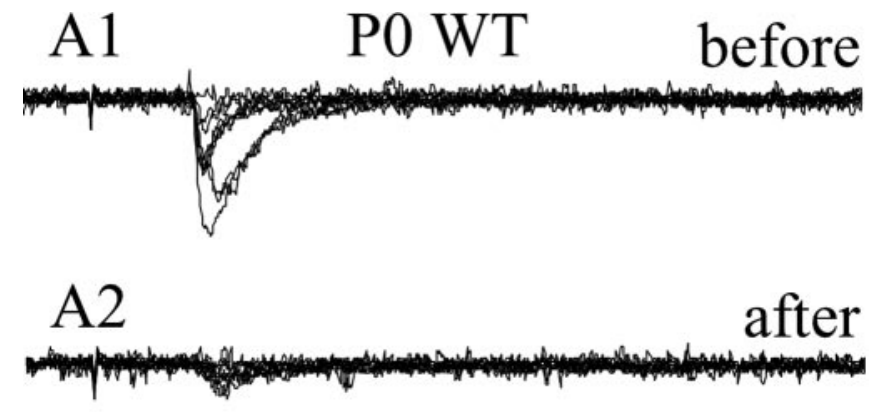

A3
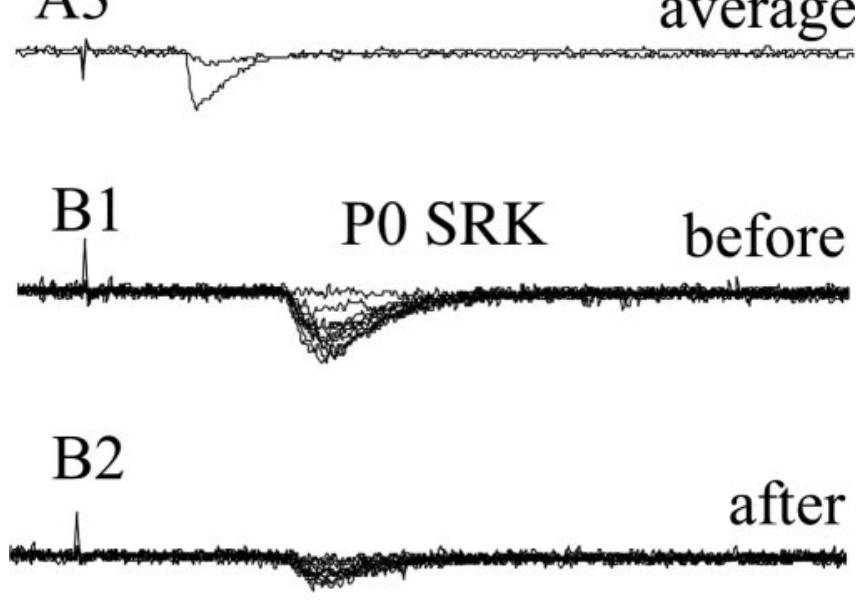

B3

average

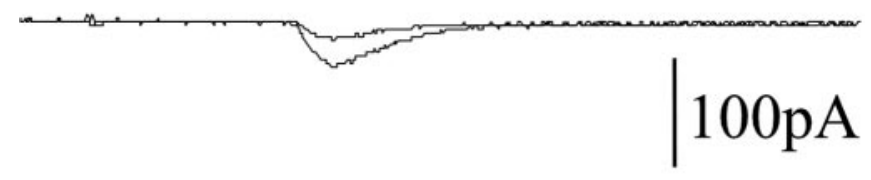

$10 \mathrm{~ms}$

Figure 8. Examples of the whole-cell current recordings obtained from a subplate cell of WT $(A)$ and a superplate cell of SRK $(B)$ at P0. Top rows $(A 1, B 1)$ represent 10 superimposed continuously recorded traces in normal artificial CSF. In both WT and SRK, synaptically evoked responses with fast decay time were observed. In SRK, latency was longer that in WT. After DNQX application $(0.25 \mu \mathrm{M}), 10$ similar traces are shown (middle rows, $A 2$ and $B 2$ ). The synaptic currents were greatly reduced, but the latencies did not change. $A 3$ and $B 3$ are superimposed average traces before and after perfusion.

ping and branching at layer IV during postnatal periods (Yamamoto et al., 2000). Because in the in vivo condition, thalamic axons extend toward subplate neurons in either WT or SRK before contacting layer IV cells, some attractive cues for primary axons might exist around the subplate or superplate neurons at embryonic stages. These cues might be dramatically altered during postnatal days. Synchronously with the increased ingrowth permissive property of the cortex, the attractive signals might diminish from the subplate and translocate to layer IV. It is also conceivable that the stopping and the branching signals operate independently (Yamamoto et al., 2000), and the branching signal itself can be responsible for the layer-specific arbor formation in SRK.
Remodeling of thalamic axons in SRK cortex during early postnatal period

Our single axon tracing experiments demonstrated that the majority of thalamocortical axons initially extend toward early generated cells (in subplate and superplate neurons), regardless of their differing relative location to other cortical layers, in both WT and SRK. Interestingly, at later stages, some of the axons in SRK did not extend to the superplate and still formed arbors in the region in which layer IV cells were located. The extent to which thalamocortical axons change their morphology and refine their arbors after their entry to the cortex has been subject of debate. Agmon et al. (1993, 1995) suggested a rather precise and definitive topography, whereas Krug et al. (1998) and Rebsam et al. (2002) argued for substantial refinement. Our present study suggests that under the conditions present in the SRK cortex, individual thalamocortical projections are capable of changing their arbors. They seem to be able to develop new branches to the middle of the cortical plate and synchronously remove substantial parts of the initial loop into the SRK superplate. It is not known, however, whether remodeling of thalamic arbors occurs on a similar scale in normal brains.

In conclusion, the present study demonstrated that synaptic responses induced by thalamic axons moved from early generated cortical neurons to later-generated neurons in both WT and SRK mutant rats. Our study suggests that the order of synapse formation with cortical cells is strictly determined during perinatal periods and that this general sequence of synapse formation may be important for the development of ultimate thalamocortical synapses.

\section{References}

Agmon A, Connors BW (1991) Thalamocortical responses of mouse somatosensory (barrel) cortex in vitro. Neuroscience 41:365-379.

Agmon A, Yang LT, O’Dowd DK, Jones EG (1993) Organized growth of thalamocortical axons from the deep tier of terminations into layer IV of mouse barrel cortex. J Neurosci 13:5365-5382.

Agmon A, Yang LT, Jones EG, O’Dowd DK (1995) Topological precision in the thalamic projection to neonatal mouse barrel cortex. J Neurosci 15:549-561.

Aikawa H, Nonaka I, Woo M, Tsugane T, Esaki K (1988) Shaking rat Kawasaki (SRK): a new neurological mutant rat in the Wistar strain. Acta Neuropathol (Berl) 76:366-372.

Allendoerfer KL, Shatz CJ (1994) The subplate, a transient neocortical structure: its role in the development of connections between thalamus and cortex. Annu Rev Neurosci 17:185-218.

Arber S (2004) Subplate neurons: bridging the gap to function in the cortex. Trends Neurosci 27:111-113.

Bicknese AR, Sheppard AM, O'Leary DD, Pearlman AL (1994) Thalamocortical axons extend along a chondroitin sulfate proteoglycan-enriched pathway coincident with the neocortical subplate and distinct from the efferent path. J Neurosci 14:3500-3510.

Bolz J, Novak N, Götz M, Bonhoeffer T (1990) Formation of target-specific neuronal projections in organotypic slice cultures from rat visual cortex. Nature 346:359-362.

Bronchti G, Katznelson A, Van Dellen A, Blakemore C, Molnár Z, Welker E (1999) Deoxyglucose mapping reveals an ordered cortical representation of whiskers in the reeler mutant mouse. Paper presented at the Fourth Joint Meeting of the Swiss Society for Neuroscience and Swiss Society of Biological Psychiatry, Zürich, Switzerland, January.

Catalano S, Robertson RT, Killackey HP (1991) Early ingrowth of thalamocortical afferents to the neocortex of the prenatal rat. Proc Natl Acad Sci USA 88:2999-3003.

Catalano SM, Robertson RT, Killackey HP (1996) Individual axon morphology and thalamocortical topography in developing rat somatosensory cortex. J Comp Neurol 367:36-53.

Caviness Jr VS (1976) Patterns of cell and fiber distribution in the neocortex of the reeler mutant mouse. J Comp Neurol 170:435-448. 
Caviness Jr VS, Frost DO, Hayes NL (1976) Barrels in somatosensory cortex of normal and reeler mutant mice. Neurosci Lett 3:7-14.

Caviness Jr VS, Crandall JE, Edwards MA (1988) The reeler malformation, implications for neocortical histogenesis. In: Cerebral cortex, Vol 7, Development and maturation of cerebral cortex (Jones EG, Peters A, eds), pp 59-89. New York: Plenum.

Crair MC, Molnár Z, Higashi S, Kurotani T, Toyama K (1993) The development of thalamocortical and intracortical connectivity in rat somatosensory "barrel" cortex imaged by optical recording. Soc Neurosci Abstr 19:705.5.

El-Husseini AE, Schnell E, Chetkovich DM, Nicoll RA, Bredt DS (2000) PSD-95 involvement in maturation of excitatory synapses. Science 290:1364-1368

Friauf E, Shatz CJ (1991) Changing patterns of synaptic input to subplate and cortical plate. J Neurophysiol 66:2059-2071.

Friauf E, McConnell SK, Shatz CJ (1990) Functional synaptic circuits in the subplate during fetal and early postnatal development of cat visual cortex. J Neurosci 10:2601-2613.

Fukumitsu H, Furukawa Y, Tsusaka M, Kinukawa H, Nitta A, Nomoto H, Mima T, Furukawa S (1998) Simultaneous expression of brain-derived neurotrophic factor and neurotrophin-3 in Cajal-Retzius, subplate and ventricular progenitor cells during early development stages of the rat cerebral cortex. Neuroscience 84:115-127.

Ghosh A, Shatz CJ (1992) Involvement of subplate neurons in the formation of ocular dominance columns. Science 255:1441-1443.

Hanganu IL, Kilb W, Luhmann HJ (2001) Spontaneous synaptic activity of subplate neurons in neonatal rat somatosensory cortex. Cereb Cortex 11:400-410.

Hanganu IL, Kilb W, Luhmann HJ (2002) Functional synaptic projections onto subplate neurons in neonatal rat somatosensory cortex J Neurosci 16:7165-7176.

Herrmann K, Antonini A, Shatz CJ (1994) Ultrastructural evidence for synaptic interactions between thalamocortical axons and subplate neurons. Eur J Neurosci 6:1729-1742.

Higashi S, Molnár Z, Kurotani T, Inokawa H, Toyama K (1996) Functional thalamocortical connections start to develop during embryonic period in the rat: an optical recording study. Soc Neurosci Abstr 22:774.9.

Higashi S, Crair MC, Kurotani T, Inokawa H, Toyama K (1999) Altered spatial patterns of functional thalamocortical connections in the barrel cortex after neonatal infraorbital nerve cut revealed by optical recording. Neuroscience 91:439-452.

Higashi S, Molnár Z, Kurotani T, Toyama K (2002) Prenatal development of neural excitation in rat thalamocortical preparations studied by optical recording. Neuroscience 115:1231-1246.

Ikeda Y, Terashima T (1997) Corticospinal tract neurons are radially malpositioned in the sensory-motor cortex of the shaking rat Kawasaki. J Comp Neurol 383:370-380.

Jones EG (1985) The thalamus. New York: Plenum.

Kageyama GH, Robertson RT (1993) Development of geniculocortical projections to visual cortex in rat: evidence early ingrowth and synaptogenesis. J Comp Neurol 335:123-148.

Kanold PO, Kara P, Reid RC, Shatz CJ (2003) Role of subplate neurons in functional maturation of visual cortical columns. Science 301:521-525.
Kikkawa S, Yamamoto T, Misaki K, Ikeda Y, Okado H, Ogawa M, Woodhams PL, Terashima T (2003) Misplicing resulting from a short deletion in the reelin gene causes reeler-like neuronal disorders in the mutant shaking rat Kawasaki. J Comp Neurol 463:303-315.

Kostovic I, Rakic P (1990) Developmental history of the transient subplate zone in the visual and somatosensory cortex of the macaque monkey and human brain. J Comp Neurol 297:441-470.

Krug C, Smith A, Thompson ID (1998) The development of topography in the hamster geniculo-cortical projection. J Neurosci 18:5766-5776.

Luskin MB, Shatz CJ (1985) Studies of the earliest-generated cells of the cat's visual cortex: cogeneration of subplate and marginal zones. J Neurosci 5:1062-1075.

McConnell SK, Ghosh A, Shatz CJ (1989) Subplate neurons pioneer the first axon pathway from the cerebral cortex. Science 245:978-982.

Molnár Z (1998) Development of thalamocortical connections. Berlin: Springer.

Molnár Z, Blakemore C (1991) Lack of regional specificity for connections formed between thalamus and cortex in coculture. Nature 351:475-477.

Molnár Z, Blakemore C (1999) Development of signals influencing the growth and termination of thalamocortical axons in organotypic culture. Exp Neurol 156:363-393.

Molnár Z, Adams R, Goffinet AM, Blakemore C (1998) The role of the first postmitotic cells in the development of thalamocortical fiber ordering in the reeler mouse. J Neurosci 18:5746-5765.

O'Brien TF, Steindler DA, Cooper NG (1987) Abnormal glial and glycoconjugate dispositions in the somatosensory cortical barrel field of the early postnatal reeler mutant mouse. Brain Res 429:309-317.

Rebsam A, Seif I, Gaspar P (2002) Refinement of thalamocortical arbors and emergence of barrel domains in the primary somatosensory cortex: a study of normal and monoamine oxidase A knock-out mice. J Neurosci 22:8541-8552.

Robertson RT, Annis CM, Baratta J, Haraldson S, Ingeman J, Kageyama GH, Kimm E, Yu J (2000) Do subplate neurons comprise a transient population of cells in developing neocortex of rats? J Comp Neurol 426:632-650.

Welt C, Steindler DA (1977) Somatosensory cortical barrels and thalamic barreloids in reeler mutant mice. Neuroscience 2:755-766.

Wong-Riley M (1979) Changes in the visual system of monocularly sutured or enucleated cats demonstrable with cytochrome oxidase histochemistry. Brain Res 171:11-28.

Yamamoto N, Kurotani T, Toyama K (1989) Neural connections between the lateral geniculate nucleus and visual cortex in vitro. Science 245:192-194.

Yamamoto N, Yamada K, Kurotani T, Toyama K (1992) Laminar specificity of extrinsic cortical connections studied in coculture preparations. Neuron 9:217-228.

Yamamoto N, Matsuyama Y, Harada A, Inui K, Murakami F, Hanamura K (2000) Characterization of factors regulating lamina-specific growth of thalamocortical axons. J Neurobiol 42:56-68.

Yuasa S, Kitoh J, Kawamura K (1994) Interactions between growing thalamocortical afferent axons and the neocortical primordium in normal and reeler mutant mice. Anat Embryol (Berl) 190:137-154. 